\title{
The effectiveness of a computer-assisted math learning program
}

Citation for published version (APA):

De Witte, K., Haelermans, C., \& Rogge, N. (2015). The effectiveness of a computer-assisted math learning program. Journal of Computer Assisted Learning, 31(4), 314-329.

https://doi.org/10.1111/jcal.12090

Document status and date:

Published: 01/08/2015

DOI:

10.1111/jcal.12090

Document Version:

Publisher's PDF, also known as Version of record

Document license:

Taverne

Please check the document version of this publication:

- A submitted manuscript is the version of the article upon submission and before peer-review. There can be important differences between the submitted version and the official published version of record.

People interested in the research are advised to contact the author for the final version of the publication, or visit the DOI to the publisher's website.

- The final author version and the galley proof are versions of the publication after peer review.

- The final published version features the final layout of the paper including the volume, issue and page numbers.

Link to publication

\footnotetext{
General rights rights.

- You may freely distribute the URL identifying the publication in the public portal. please follow below link for the End User Agreement:

www.umlib.nl/taverne-license

Take down policy

If you believe that this document breaches copyright please contact us at:

repository@maastrichtuniversity.nl

providing details and we will investigate your claim.
}

Copyright and moral rights for the publications made accessible in the public portal are retained by the authors and/or other copyright owners and it is a condition of accessing publications that users recognise and abide by the legal requirements associated with these

- Users may download and print one copy of any publication from the public portal for the purpose of private study or research.

- You may not further distribute the material or use it for any profit-making activity or commercial gain

If the publication is distributed under the terms of Article $25 \mathrm{fa}$ of the Dutch Copyright Act, indicated by the "Taverne" license above, 


\title{
Journal of Computer Assisted Learning
}

\section{The effectiveness of a computer-assisted math learning program}

\author{
K. De Witte, ${ }^{*} \dagger$ C. Haelermanst‡ \& N. Rogge*§ \\ *Faculty of Business and Economics, Katholieke Universiteit Leuven (KULeuven), Leuven, Belgium \\ TTIER, Faculty of Economics and Business, Maastricht University, Maastricht, The Netherlands \\ FIPSE Studies, Delft University of Technology, Delft, The Netherlands \\ $\S$ Centre for Economics \& Management (CEM), Hogeschool-Universiteit Brussel (HUBrussel), Brussels, Belgium
}

\begin{abstract}
Computer-assisted instruction (CAI) programs are considered as a way to improve learning outcomes of students. However, little is known on the schools who implement such programs as well as on the effectiveness of similar information and communication technology programs. We provide a literature review that pays special attention to the existing causal evidence of computer-assisted programs on learning outcomes. The paper relies on a rich data set consisting of (i) pupil-level information on the use of a Dutch computer-assisted program and (ii) detailed school-level information on, among others, outcomes on national exams. The results suggest that schools with lower educational attainments use more frequently CAI programs. This suggests that they use CAI programs to catch up on learning outcomes. Moreover, using an instrumental variable design, we argue that given the participation in the CAI program, making more exercises leads to higher test results. Working with a CAI program seems therefore effective.
\end{abstract}

Keywords computer-assisted instruction, effectiveness, mathematics, secondary education.

JEL-classification: I21; D61

\section{Introduction}

Investment in information and communication technology (ICT) infrastructure was one of the key priorities of education policies of countries all over the world over the past decades. In the European Union (EU), for instance, the European Commission developed several action plans that aimed at implementing and integrating ICT into primary schools, secondary schools, colleges and universities. An example of such an action plan was the e-Learning Initiative (European Commission, 2000). This policy was adopted by the

Accepted: 11 October 2014

Correspondence: Kristof De Witte, TIER, Maastricht University, Kapoenstraat 2, Maastricht 6200 MD, The Netherlands. Email: kristof.dewitte@kuleuven.be; k.dewitte@maastrichtuniversity.nl
European Commission in the year 2000 with the primary purpose of improving the quality of learning by increasing pupils' access to ICT facilities in schools. As a result, each European Member State developed national strategies to foster the integration and use of ICT in education. The core objective of most of these strategies was on investing public resources in the implementation of ICT in education. Overall, the results of these policies are positive for the EU Member States. Several academic and non-academic studies have indicated that schools are much better equipped with ICT equipment compared with a decade ago. The ICT infrastructure in schools improved considerably both quantitatively as well as qualitatively. For example, for the Netherlands, the ratio of computers to pupils increased gradually to an average figure of one computer for every five pupils (European Schoolnet, 
2013). As noted in the country profile report of the Netherlands (European Schoolnet, 2013), the schools in the Netherlands are among the best equipped schools in the EU in terms of ICT infrastructure. Moreover, whereas before there were considerable differences in the availability and the quality of the ICT infrastructure across schools, these differences became much smaller in the Netherlands.

With significant amounts of resources (both public and private resources, yet, for the Netherlands it concerns mostly public resources) being spent on hardware and software in the classrooms of primary and secondary schools, there is an increasing call for accountability on the school administrators, the teachers and the pupils. It is asked whether the large investments on ICT have paid off in terms of improving pupil learning outcomes. Essentially, this boils down to answering the question whether the use of technology in schools in general and in classrooms for both teaching and/or learning, more in particular, has actually enabled pupils to realize better learning outcomes. The debate is no longer on whether or not computers should be integrated into the educational system. Rather, the debate is on how the use of educational technology in teaching and learning impacts the pupils' learning outcomes, attitudes and experiences. This shift in focus resulted in an increasing number of empirical research-based studies on the effects of educational technology.

\section{A controversial debate}

The debate on the role of educational technology in the classroom is a long-standing and highly controversial one. One of the key reasons for this continuing controversy seems to be the involvement of multiple stakeholders (such as pupils, pupils' parents, teachers, school management, policymakers, educational experts) with sometimes diverging interests. Particularly, the question of whether or not the use of educational technology has benefited the pupils' knowledge or the learning experience has stirred a lot of controversy. As in all interesting debates, there are both believers and non-believers.

The believers argue that educational technology when used properly in the classrooms may provide support to the teacher in teaching the course material and help the pupil in mastering the required concepts more easily. They typically refer to studies confirming a positive relationship between the use of educational technology in teaching and learning and the pupils' learning outcomes, their attitudes towards and their experiences with learning. One of the first proponents of the use of technology in the classroom was the psychologist Skinner. In the 1950s, Skinner (1954, 1958) published several papers in which he explains his belief that the use of technology in teaching and learning (he uses the term 'teaching machines') might benefit the learning efficiency of pupils. Thanks to the possibilities of repetition and classroom differentiation, advocates have invoked that the use of educational technology in teaching and learning may, among other things, help pupils in putting greater focus on understanding the more difficult and complex concepts (Doerr \& Zangor, 2000) as well as help them in developing a conceptual understanding of such concepts (Kaput, Hegedus, \& Lesh, 2007; Kebritch, Hirumi, \& Bai, 2010). Other points of strength of educational technology are the interactive nature with high interaction frequency between teacher-system-pupil and the adaptive nature which enables to customize instruction and feedback for the needs of the individual pupil (Shute \& Zapata-Rivera, 2007; Wenglinsky, 1998). Wenglinsky (1998), for instance, discussed that educational software can provide pupils with the opportunity to self-organize their learning. Most proponents are also convinced that educational technology can play an important role in the democratization of access to education in the sense that it can enable pupils in different settings (particularly students in more disadvantaged settings) to have more and better learning opportunities. With these positive effects in mind, they believe that investing considerable (public or private) resources in the implementation of educational technology in schools is worthwhile.

The non-believers and the critics (e.g., Fuchs \& Wößmann, 2004; Honey, Culp, \& Carrigg, 2000) are much less enthusiastic and more sceptical about the use of technology in the classroom. They (strongly) contest this alleged positive impact of educational technology on the pupils' achievements and warn that the use of educational technology should not be considered a panacea to the problem of improving pupils' learning outcomes in education. They believe that if there is an impact on learning effectiveness then at best this impact is only marginal. Some of the sceptics even believe that this idea of a positive impact of educational 
technology on the teaching and learning efforts of teachers and pupils is just a notion invoked by certain stakeholders who benefit from the presence of this perceived link (not the least the developers of such educational hardware and/or software). Some of the non-believers even strongly argue against the use of technology in classrooms, thereby claiming that the pupils' test achievements may even be negatively associated with technology use. They fear, among other things, that the use of computers or other educational tools in the classroom may distract pupils instead of helping them in mastering educational concepts. Another point of worry is that the use of educational technology may undermine the teacher-pupil relationship and reduce the interaction between teachers and pupils.

\section{Evidence}

Summarizing the findings of earlier literature is an intricate matter. Overall, it seems that the evidence is inconclusive with some studies indicating positive effects (e.g., Kulik, 2003; Murphy, Penuel, Means, Korbak, \& Whaley, 2001), other studies showing no strong impact (e.g., Angrist \& Lavy, 2002) and some studies finding negative effects (e.g., Campuzano, Dynarski, Agodini, \& Rall, 2009; Spiezia, 2010) of using computer software in teaching and learning. The mixed results are certainly to some extent due to the complexity of the relationship between ICT and learning. Other reasons are the wide variety of assumptions that have been made by research studies and the fact that the impact of educational technology has been studied from different perspectives (e.g., pedagogical, sociological, computer sciences and economics), in different teaching and learning environments and using different methodologies. All of this makes that the findings of one study about the effectiveness of educational technology cannot be generalized beyond the teaching and learning context in which the study was performed. Moreover, as remarked by some researchers (e.g., Cheung \& Slavin, 2013; Condie \& Munro, 2007; Cox \& Marshall, 2007), a large majority of the past studies suffer from design flaws and methodological or conceptual weaknesses which raise doubt about the validity of their findings. Several of these limitations are discussed and tackled in this paper.

\section{Contributions}

The current paper contributes to this expanding literature in several ways. First, the primary objective of this paper is to examine the effectiveness of an online and adaptive educational tool in learning mathematics in secondary school. The key feature of this computerassisted instruction (CAI) tool is that it provides each student with an individual training package based on his or her test results. This training package consists of a wide range of explanatory movies (e.g., screencasts), theory and exercises. We exploit the rich data set, which is logged by the program, to examine the influence of CAI tool on students' test scores.

Second, we aim to contribute to the theory and literature on e-learning by discussing the effect of a CAI tool. This tool is based on many learning theories, but mainly adds to the discussion on self-efficacy in e-learning, as it calls upon students' self-efficacy when and how much they practise.

Third, we address some of the methodological concerns typically observed in past research studies. Using an instrumental variable (IV) technique, we focus on causal evidence. The instrument is deduced from the way teachers deal with the CAI tool. We exploit the fact that some students are more exposed to the program than other students. Using IVs with class and school fixed effects, we obtain causal evidence on the relationship between making online exercises and test results.

In particular, this paper tests two research questions:

1. Do schools with lower educational attainments use CAI programs more frequently?

2. Does more intense exposure to the CAI program cause higher test scores?

This article is organized as follows. The ensuing section presents the main findings of previous studies on the association between ICT use and pupils' learning outcomes. We focus on both the different methodologies as well as on literature on ICT in general and CAI tools in particular. A next section presents the data and introduces the computer-assisted tool. This is followed by a section presenting the main results for the first research question, while after which we present the results for the second question. The final section concludes by summarizing the key findings of this article and providing policy recommendations. 


\section{Literature review}

\section{e-Learning: theories and models}

Computer-assisted instruction is strongly associated with e-learning, a term that has been broadly used in education since the 1990s. In fact, e-learning is typically employed as common term for teaching and training methods and initiatives that offer learning material, course communications and the delivery of course content electronically through technology mediation (Swan, 2003). The key feature of e-learning tools such as CAI is the use of technology in teaching and learning. There is a variety of conceptual models and theories in the academic literature on e-learning that contribute to developing a better understanding of particular aspects of e-learning. Examples of theories and models that have been discussed in the literature include, among others, the technology acceptance model (after Davis, 1989), the constructivist theory of learning (Jonassen, Peck, \& Wilson, 1999), the cognitive load theory (after Sweller, 1988), the theory of self-efficacy in learning (after Bandura, 1997) and technology-mediated learning framework (Alavi \& Leidner, 2001). Each of these models partially contributed to understanding how e-learning programs can be effective in education and training.

Some of these models focused on the role of technology in e-learning. As an example, the technology acceptance model, a model that was initially developed to study and explain computer-usage behaviour and the users' tendency to accept technology, proved to be very appropriate for examining and predicting learner's satisfaction with e-learning (see, among others, Arbaugh, 2002; Cheng, 2011; Liu, Liao, \& Pratt, 2009; Pituch \& Lee, 2006; Wu, Tsai, Chen, \& Wu, 2006). According to this model, for an e-learning tool to be effective, it needs to make the learner's experience a feeling of usefulness and ease of use. The more successful the e-learning tool in generating such emotions, the more positive will be the learner towards using e-learning tools in learning and the better their learning experiences and satisfaction. According to Alavi and Leidner's framework for technology-mediated learning, e-learning tools will only be effective in generating good outcomes when technology and pedagogy are properly integrated.
Other theories scrutinized more the role of the learning process in e-learning. For instance, the constructivist theory of learning suggests that learning is essentially a process that involves guiding and helping learners in constructing own meanings from experiences. More in particular, according to this model, knowledge is something that has to be transferred to the learner. Yet, this model also suggests that it is the learner's ability and preferences to construct that knowledge within him or her which determine the actual learning (Sahasrabudhe \& Kanungo, 2014). Somewhat related to this idea of this theory, the cognitivist theory of learning posits that perception, insight and meaning contribute to the actual learning. This theory considers learning to be an internal intellectual process where learners interpret data acquired through senses (Piaget, 1970). The cognitive load theory, a theory popular in the field of learning and instruction (see Paas, Renkl, \& Sweller, 2003 for an overview), has recently also been discussed in the context of e-learning (Van Merriënboer \& Ayres, 2005).

The research on self-efficacy puts forward that the ability of learners to work with e-learning tools is a key success factor of e-learning (Marakas, Yi, \& Johnson, 1998). The intuition of this theory is that highly efficacious individual learners are more confident in accomplishing e-learning activities. As such, they are focusing more on the processing and understanding of the message content and learning. On the other hand, individuals with low self-efficacy tend to focus more on the barriers they must overcome before being able to use the e-learning tool effectively. This implies that less cognitive resources are being spent on the learning itself.

In general, most of the aforementioned pedagogical theories support the effectiveness of e-learning. For instance, several of these theories support the idea that e-learning conjures constructivist principles (for a discussion, see, e.g., Macdonald, 2004). Before concluding, it is important to emphasize that the list of theories and models presented above is not inclusive. Examples of other theories that have been discussed in the context of e-learning are the self-determination theory (Roca \& Gagné, 2008), social cognitive theory (Bandura, 1997) and the social influence model (proposed by Fulk, Schmitz, \& Steinfield, 1990). Recently, most of the aforementioned theories have also been discussed and examined empirically in the e-learning context in 
several interesting studies (e.g., Johnson, Hornik, \& Salas, 2008; Sahasrabudhe \& Kanungo, 2014; Sun, Tsai, Finger, Chen, \& Yeh, 2008; Van Merriënboer \& Ayres, 2005).

\section{Quantitative versus qualitative studies ${ }^{1}$}

The previous studies on the impact of CAI tools in the teaching and learning of mathematics can be largely classified into two groups according to whether they used qualitative or quantitative approaches. Qualitative studies frequently use semi-structured, in-depth interviews to collect information about the perceptions, attitudes or opinions of the different stakeholders in education (e.g., the pupils, the teachers, the school directors, educational experts). Examples are Schacter (2001) and Reimer and Mayer (2005). Reimer and Mayer (2005), for instance, employed a qualitative approach to investigate the impact of CAI tools in the teaching and learning of mathematics. The qualitative analysis consisted of interviewing pupils as well as administering an attitude survey among them to examine the impact of CAI tools. In particular, the effect of virtual manipulative computer applets on 3rdgrade pupils' achievement levels and attitudes. The results of this qualitative examination showed that the use of computer-based virtual manipulation in teaching mathematical concepts to pupils helps pupils in understanding fractions. One of the explanations for this result, as discussed by Reimer and Mayer, is that the use of computer-based virtual manipulation enables the teachers to provide the pupils with more immediate and individual-specific, and hence better, feedback.

The majority of the studies in the literature used a quantitative analysis approach to examine the impact of technology in education. Typically, studies employed statistical analysis techniques such as simple correlation analysis (McAlister, Dunn, \& Quinn, 2005), regression techniques (Angrist \& Lavy, 2002), (M)AN(C)OVA (Pilli \& Aksu, 2013) and randomized control trial designs (Papastergiou, 2009; Potocki, Ecalle, \& Magnan, 2013). The results of the qualitative studies are summarized in multiple interesting metaanalyses. Examples of meta-analyses include Kulik and Kulik (1991), Kulik (1994, 2003), Murphy et al. (2001), Blok, Oostdam, Otter, and Overmaat (2002), Christmann and Badgett (2000, 2003), Goldberg, Russell, and Cook (2003), Rayne and Baggott (2004), and Cox and Abbott (2004). We briefly describe the main findings of the most recent meta-analyses (i.e., the meta-analyses that appeared since 2000).

Murphy et al. (2001) considered 195 (quasi-) experimental studies conducted in the 90s. Minimum methodological requirements were imposed to select among these 195 studies the ones qualified for more detailed analysis. This resulted in a subset of 31 studies. Based on the outcomes of these studies, Murphy et al. computed an impressive average effect size of 0.45 for mathematics (i.e., as a proportion of the standard deviation of the mathematics test scores).

Christmann and Badgett (2000) examined the difference in achievement levels between pupils who were taught by the traditional instruction approach (control group) and pupils who had classes in which a CAI tool was used as a supplement to the traditional classes (the experimental group). In doing so, they compiled data from 26 studies. The overall results suggested a mean effect size of 0.127 . Hence, pupils who were taught and who learned mathematics via educational software as supplement to traditional teaching displayed higher achievement levels compared with the other pupils in the control group. Moreover, as denoted by Christmann and Badget, the achievement level of the typical pupil in the experimental group increased from the 50th percentile to the 55th percentile.

Rayne and Baggott (2004) performed a metaanalysis of 40 studies that examined the differences in effectiveness of a $100 \%$ traditional teaching approach and a teaching approach that supplements traditional teaching with CAI (hence, a mixture of traditional and computer-assisted teaching). They concluded that the combined traditional-CAI teaching approach was more effective in that it enables pupils to realize higher levels of achievement compared with the pupils who were taught by the $100 \%$ traditional teaching approach.

\section{Causal evidence on educational technology}

Typically, it is very difficult to estimate causal relations between the use of educational technology and the changes in the pupils' learning outcomes. As nicely formulated by Biagi and Loi (2013, p. 29): 'in practice, we seldom have the chance to go beyond measures of association because, even if we have a clear view on the causal relationship between the left-hand and the righthand side variables, we are not able to identify it 
through lack of data.' We observe in earlier literature various studies focusing on associations (e.g., Fuchs \& Wößmann, 2004; Kubiatko \& Vlckova, 2010; Luu \& Freeman, 2011; Notten \& Kraaykamp, 2009; Spiezia, 2010; Wittwer \& Senkbeil, 2008). However, recently, this trend is somewhat changing. Probably due to more data availability and increased attention to causality, an increasing number of studies employed an experimental or quasi-experimental approach to examine how the use of technology in the classroom, in the school or at home relates to the pupils' learning outcomes. While correlational studies have their merits, we focus on the causal evidence and the way it has been revealed.

Machin, McNally, and Silva (2007) used data on the educational outcomes in the UK primary schools for the period 1999-2003 to estimate the causal impact of ICT investments made during these periods. To control for the potential issue of endogeneity in the investment variable, they employed an IV approach. The IV analysis revealed a significant positive causal impact. Banerjee, Cole, Duflo, and Linden (2007) scrutinized the results of a randomized policy implemented by two regions in India with the objective of improving the quality of education in urban slums. The key finding was that the use of educational technology developed to enforce the mathematical skills of pupils did in fact succeed in realizing this objective. However, the researchers underlined that this positive result was limited to the domain of mathematics. No positive results were found for the pupils' performances in other domains. Leuven, Lindahl, Oosterbeek, and Webbink (2004) investigated how a subsidy established by the government in the Netherlands for the purchase of educational technology (both hardware and software) influenced the learning outcomes of disadvantaged pupils in primary school. To examine the impact of this subsidy, the authors exploited the discontinuity in this subsidy (with some of the schools with disadvantaged pupils being eligible for the subsidy and other schools not) to estimate the effect of educational technology on the learning outcomes of disadvantaged pupils. More precisely, using a difference-indifferences framework, they compared the change in pupils' performances (i.e., the difference in pre- and post-test scores) between the disadvantaged pupils in schools who received the subsidy and their counterparts in schools who did not. The results showed that the subsidy had a negative impact on the pupils' learn- ing outcomes. In other words, disadvantaged pupils in schools who received the subsidy achieved lower changes in test scores compared with pupils in schools who did not qualify for this subsidy. Finally, Rouse, Krueger, and Markman (2004) focused on the influence of an instruction technology on the reading and language skills of pupils in the USA. Using a randomization framework, they found a limited positive impact on the language skills. Dynarski et al. (2007) employed an experimental design in which the changes in pre- and post-test scores are compared between pupils who used various software tools in the classroom (treatment group) and the pupils who did not (control group). In the study, 439 volunteer teachers participated in the experiment. This resulted in data for approximately 9.500 pupils. A comparison of the pupils' pre- and post-test scores between the pupils in the treatment and control groups showed that on average there is no considerable difference between the users and non-users. This suggests that the impact of the use of educational technology on pupils' learning outcomes in mathematics and reading is questionable.

\section{Causal evidence for computer-assisted tools}

As remarked by, among others, Beal, Arroyo, Cohen, and Woolf (2010), there is a large variety of educational technology, ranging from simple and static ('old style') tools and the more innovative, dynamic, interactive and flexible tools. The more simplistic tools are typically less flexible and less interactive. They aid pupils in certain standard tasks such as performing computations (examples are calculators, excel software). The most recent educational technology is more flexible and more interactive in the sense that it is adaptive to the needs of each individual pupil. Examples of such instruments (hardware and/or software) include LOGO, Derive, Cabri, Mathematica, Coypu, Geometric Supposer, Geometer's Sketchpad, Cognitive Tutor Algebra, Larson Algebra, Plato Algebra and Frizbi Mathematics 4. The effectiveness of most of these software tools has been examined by research studies in (quasi-)experimental designs.

Dynarski et al. (2007), for instance, investigated by an experimental design how the use of Achieve Now, iLearn Math and Larson Pre-Algebra in the teaching of mathematics in the 6th grade was related to the pupils' test outcomes. The three software products were 
developed primarily for providing tutorial and practice opportunities. Overall, the results suggested that there were no significant differences in the test scores between users and non-users. Nevertheless, large differences were observed across schools. In addition, a series of statistical tests indicated that the included classroom-, teacher- (e.g., teacher experience, teacher gender, teacher education level), and school-level characteristics were not statistically significantly related to the observed differences in test scores.

Pilli and Aksu (2013) employed a quasi-experimental research design to examine the impact of educational software for mathematics on 4th-grade pupils' achievements in mathematics, the pupils' attitudes towards mathematics and computer-assisted teaching and learning, as well as the retention of mathematical knowledge. They found that the educational software is an effective tool for teaching and learning mathematics in the sense that pupils who used the software in the classrooms achieved higher test scores and had more positive attitudes towards mathematics.

Roschelle et al. (2010) focus in an experimental design on a software tool that was developed with the purpose of enabling a large group of pupils to learn more advanced mathematical concepts and skills in Texas. They identified a positive significant impact of the use of the program on pupils' mathematics achievements. Roschelle et al. conclude that the CAI tool is an effective tool to enhance pupils' knowledge of more advanced mathematics.

Edwards and Quesada (2007) argued that Cabri3D offers, among other things, three important advantages in the teaching and learning of mathematics. One such advantage is that the visualization aspects of the software tool help pupils in better understanding threedimensional figures and shapes. Another advantage is that it provides information that helps students in understanding the relationship between two- and threedimensional concepts. The effectiveness of the regular version of Cabri as educational software in teaching and learning of mathematics was examined more recently by Köklü and Topçu (2012). They focused on the impact of Cabri among 10th graders and found that pupils who used Cabri had a better understanding of the concepts about graphs of quadratic functions. More precisely, whereas pupils who were taught these concepts by the traditional approach had more difficulties in understanding these concepts, the ones who used Cabri in their learning experienced fewer difficulties.

Koedinger, McLaughlin, and Heffernan (2010) investigated the effect of ASSISTments on the math test scores of 7th-grade pupils in middle school. ASSISTments is a Web-based tutor system designed for teaching mathematics. A key feature of this system is that it aims at addressing the need for timely pupils' assessment while at the same time providing instruction to the pupils. By doing so, the tutor system avoids the loss of instruction time that typically occurs during assessment. Koedinger et al. used a quasi-experimental approach to measure the effect of the ASSISTments tool. The sample consisted of 1240 pupils. Koedinger and his colleagues found that the use of the Web-based tutor system for teaching mathematics is effective in improving pupils' learning of mathematics. Moreover, the comparison between the improvements in math test scores of pupils in the treatment and control groups also indicated that the largest improvements in the treatment were obtained for special education pupils. This suggests that the ASSISTments system is particularly effective for this group of pupils as it enables them to catch up (at least to some extent) with the other pupils. Note that a similar result was also found by Bouck and Flanagan (2009) for the use of other types of assistive technology in the teaching and learning of mathematics.

\section{Computer-assisted tool and data}

\section{The computer-assisted tool}

This paper considers a Dutch computer-assisted online tool called Gotit?!. The hallmark of the education software Gotit?! is that it was created through consideration of the best approaches of teaching mathematics as well as the needs (cognitive, psychological, etc.) of the students. The CAI tool offers a large amount of exercises of different difficulty levels. This enables each pupil to organize the work and progress at a rate consistent with his/her own level of ability. This allows the teacher to differentiate within the class. Pupils who experience fewer difficulties with the theory and advance quickly in solving exercises can go to exercises of higher difficulty level without being slowed down by pupils who progress more slowly. As the tool is easy to master, it is unlikely that there is a significant difference among teachers in the mastery of the tool. 
The CAI tool is adaptive in that it adjusts its exercises to the knowledge and level of the student. Gotit?! provides pupils with tips on organization and skills for solving exercises. All of this may benefit the pupils' confidence in the learning content, improve their metacognitive skills and provide a way for skill drill (i.e., practising an activity until it becomes automatic). The content is organized along 11 subjects. These include, for example, additions, multiplications or counting principles.

On top of this, the Gotit?! system offers features that give quick and continuous feedback to the teacher on pupils' learning progress both at the level of the individual pupil as well as the classroom. More precisely, the feedback and control system comprises tools for tracking each individual pupil's step-by-step progress so that at each moment an accurate overview of his/her competence level is possible. In this way, the teacher can monitor which pupils realize the milestones and which pupils require additional attention. Based on this continuous stream of information on pupils' progress, the teacher can determine whether an adjustment in the instruction approach or any other type of remediation is warranted for the class as a whole or for one or more individual pupils. In addition, Gotit?! also includes communication features that enable teachers to interact and communicate with the pupils both at classroom level as well as individually. Depending on the circumstances, the teacher can decide to provide feedback to all pupils in the class, a subgroup of pupils or just one individual pupil.

\section{The CAI content}

The Dutch national performance standards formulated for middle school students by the Meijerink Commission (Commissie Meijerink, 2008) distinguish four mathematics domains: numbers, proportions, measurement and associations. Each domain consists of two to four topics, for example, number consists of addition and subtraction, multiplication, fractions and decimal numbers, whereas proportion consists of proportional problems and percentages. All four domains and their subtopics are covered by the CAI tool and are available for students to practise with, depending on their level in these domains/topics. All domains consist of questions that either test/practise whether students know the language and understand what is expected of them, whether they are able to connect aspects of the domain and whether they are actually able to do the math that is expected of them in this domain.

In the CAI, students have their personal knowledge map, which states how many of the exercises and tests a student has made, in total and per domain, by showing percentages. It also shows the results so far by domain (e.g., so far, you have scored $81 \%$ on numbers and $63 \%$ on proportions). Furthermore, the knowledge map shows which test they have made and should make, which exercises they have done (and the score) and which ones they should do, and which explanation movies are relevant for them. All of this is sorted by the different domains. Students can decide in which domain they want to practise and in which subtopic of that domain. The knowledge map is developed to provide an overview of what has been done and is still to be done, and also to motivate the students by showing previous test scores and by counting how much has already been done.

The pre-test consists of between 22 and 55 questions, depending on the level and the composition of the test. After the pre-test, a certain set of exercises is available for each individual student, and this set is adapted while practising in the tool.

\section{Data collection and the sample}

Various studies in earlier literature suffer from the use of small samples. Numerous studies, for instance, used sample sizes of less than 50 pupils. Researchers typically experience a dilemma in which they have to trade off the choice for a large-scale study with the choice for a detailed study of the impact of very specific uses or types of educational technology (i.e., a particular educational software product). This paper does not suffer from this drawback. Data were provided by the publisher that developed the Gotit?! software (i.e., ThiemeMeulenhoff). The data include all users of the online tool. The data consist of two parts: the first part is the information that the school has to fill out in the system (e.g., class, education type) and the second part is the data that are registered automatically through the online Gotit?! database when students practise and take tests. Schools were encouraged by ThiemeMeulenhoff to fill out the first part as good as possible, but unfortunately the data still show that almost half of the schools were not consistent in filling out the 
educational level of the students and a small share of the schools did not fill out the class. Therefore, we decided to not take level of education directly into account, but only via the class. After removing data with incomplete cells or incorrect logs of time (we removed students whose recorded time to complete the pre-test was more than $3 \mathrm{~h}$, while the median student took less than $1 \mathrm{~h}$ for the test), the cross-sectional sample consists of 9898 pupils in the first three grades of secondary education in 2012. In addition, we augmented the pupil-level data with school-level information from the Ministry of Education, Culture and Science. Schools are obliged to submit these data yearly in preset formats. The most recent year available is school year 2011-2012. This information provides us with additional insights in the educational attainments of the school, the allocation of the school budget and the composition of the school in terms of share of students from disadvantageous backgrounds. Even more importantly, this data source provides us with information on the school average of the national and school exam. In the final years of secondary education, all students in the Netherlands have to take two exams for each course in which they received lessons (inde- pendent of the educational track). The former exam the 'national exam' - is an absolute assessment with criterion - referencing which is uniform for all subjects and schools in the Netherlands (see De Witte, Geys, \& Solondz, 2014 for a discussion). The latter exam - the 'school exam' - has fewer quality controls in its construction and evaluation as it is set up and corrected only by a school's teachers. Aggregate information on the school and national exam is publicly available.

\section{Descriptive statistics}

The descriptive statistics are presented in Table 1. The 'average pre-test' is computed as the average of the pre-tests of all students at a school location. It ranges between 28 and 73, with an average of 59 (note that the maximum possible is 100). The 'post-test scores' consist of the average score of the various subjects the student took. It ranges between 0 and 1 . The 'number of exercises' the student took in the CAI tool varies between 1 and 1248. Despite this high maximum, 75\% of the students took 62 exercises.

We further have information on the student's ability. The pre-test that students took ranges between 4 and

Table 1. Descriptive Statistics

\begin{tabular}{|c|c|c|c|c|c|c|}
\hline Variable & $\begin{array}{l}\text { No. of } \\
\text { observations }\end{array}$ & Mean & SD & Min & Median & Max \\
\hline \multicolumn{7}{|l|}{ Variables of interest } \\
\hline Average pre-test (school level) & 9898 & 59.17 & 4.94 & 28 & 59.25 & 73 \\
\hline Post-test scores (student level) & 9898 & 0.64 & 0.19 & 0 & 0.66 & 1 \\
\hline Number of exercises & 9898 & 50.52 & 65.53 & 1 & 30 & 1248 \\
\hline \multicolumn{7}{|l|}{ Student ability } \\
\hline Pre-test - score (student level) & 9898 & 59.11 & 12.32 & 4 & 60 & 96 \\
\hline Pre-test - time in seconds (student level) & 9898 & 3320.85 & 2034.67 & 0 & 3409.5 & 9996 \\
\hline \multicolumn{7}{|l|}{ Instrument } \\
\hline Exposure to $\mathrm{CAl}$ - continuous & 9898 & 3.54 & 2.82 & 1 & 3 & 11 \\
\hline Exposure to CAI - dummy (little - extensive) & 5478 & 0.1 & 0.3 & 0 & 0 & 1 \\
\hline \multicolumn{7}{|l|}{ Control variables } \\
\hline Average national exam (school level) & 9898 & 6.35 & 0.17 & 5.78 & 6.37 & 6.71 \\
\hline Average school exam (school level) & 9898 & 6.45 & 0.12 & 6.08 & 6.46 & 6.8 \\
\hline School size (school level) & 9898 & 2467.94 & 1169.59 & 400 & 2284.00 & 5641.00 \\
\hline $\begin{array}{l}\text { Number of teachers per student (1000 FTE - } \\
\text { school level) }\end{array}$ & 9898 & 0.16 & 0.08 & 0.02 & 0.15 & 0.38 \\
\hline Costs for materials (million euro - school level) & 9898 & 2.35 & 1.62 & 0.35 & 1.91 & 7.91 \\
\hline Dropout percentage (school level) & 9898 & 1.05 & 0.46 & 0.17 & 0.99 & 4.6 \\
\hline$\%$ Disadvantaged students (school) & 9898 & 5.14 & 7.66 & 0 & 1.4 & 41.8 \\
\hline$\%$ Supportive ability track (school) & 9898 & 11.99 & 11.58 & 0 & 9.42 & 45.67 \\
\hline \multicolumn{7}{|l|}{ Fixed effects } \\
\hline Class & & & & & & 1947 \\
\hline Class and school & & & & & & 2239 \\
\hline
\end{tabular}

$\mathrm{CAl}=$ computer-assisted instruction; FTE = full time equivalent. 
96, with an average of 59. Students took this pre-test in, on average, $55 \mathrm{~min}$. Twenty-five per cent of the student took maximum $38 \mathrm{~min}$ for the pre-test.

We observe a broad set of control variables at the school level. First, the school average of the national exam amounts, on average, to 6.35. This is slightly lower than the mean of the school average of the school exam, which equals 6.45. It is commonly observed in the Netherlands that the school exam is slightly higher graded than the standardized national exam. The number of teachers (expressed in full time equivalents) is on average 160 per school (note: this denotes the school group rather than the school location). This should be compared with the average number of students per school, which amounts to 2467. This indicates that the average class size counts about 15 students. The dropout percentage is standardized such that the median school has a percentage of 1 . We observe information on the costs for materials (expressed in million euros), the percentage of students coming from disadvantaged neighbourhoods (mean $5.1 \%$ ) and the percentage of students in supportive ability tracks (mean 12\%).

Finally, we observe in the data 128 school groups with 171 school locations, 1947 different classes and 2239 different combinations of school locations and classes.

\section{Do schools use computer-assisted learning tools to improve learning outcomes?}

\section{Model specification}

To examine the first research question, we estimate a regression that correlates the intensity use and school attainments. We proxy the intensity of working with the CAI tool in two ways. First, we consider the number of exercises a student has made. The more exercises, the more intense the student has worked with the tool. Second, we consider the number of subjects the student has successfully completed. By combining the two outcome variables, complementary information is obtained. The school attainments, as the independent variable, are measured by the outcomes on the school exam and the nationwide standardized national exam.

In the regression, we also control for observed heterogeneity. This includes, first, the student attainments on the pre-test. Including pre-test information is important to capture potential endogeneity arising from unobserved student's ability. More able students require less exercises. We observe a significant, although low, correlation between the pre-test (student level) and the nationwide exam (school level). In a similar vein, we include as a second control variable the time the student needs to write the pre-test. Whereas the first two control variables are at the student level, the other control variables are at the school (location) level. They include the level of early school leaving, the percentage of students from disadvantaged neighbourhoods (Armoede Probleem Cummulatie Gebied (APCG)) and the percentage of students at the school in supportive ability tracks (Leerweg Ondersteunend onderwijs (LWOO)).

Finally, we include class fixed effects and an error term in the regressions. Earlier literature argued that including the fixed effects is important as it captures the nested structure in the data. Pupils are being nested within classes (and, hence, teachers) and schools. As discussed by Roschelle et al. (2010), not accounting for this nesting can be an important limitation as it does not rule out the presence of clustering effects in the results.

\section{Results}

The results are presented in Table 2. The first two model specifications provide the results for the number of completed subjects as outcome variable. The last two model specifications have the number of exercises as outcome. We observe that the higher the average national exam grade, the less subjects and exercises are completed (i.e., a negative significant correlation of -4.47). The same yields for the school exam, which has a negative significant correlation in model 2 of -3.75 . On the opposite, as can be observed from models 3 and 4 , students in schools with lower national exam outcomes make more exercises (negative significant correlation of -89.67) and more subjects - controlled for individual abilities and class fixed effects.

We further observe that, at the individual level, higher pre-test scores are positively correlated (coefficient of 0.04 ) with the intensity that the program is used. This is no longer significantly different from zero if the number of exercises is used as an outcome. In addition, the faster the student worked in the pre-test, the less subjects and exercises he/she completed. It should be noted that all the estimations include class fixed effects such that observed and unobserved 
Table 2. Relationship Between Learning Outcomes and Intensity of Program Use

\begin{tabular}{lcccc}
\hline & Model 1 & Model 2 & Model 3 & Model 4 \\
\hline Independent variable & Subject & Subject & Exercises & Exercises \\
Average national exam (school level) & $-4.4697 * * *$ & -0.0136 & $-89.6699 * * *$ & -37.611 \\
Average school exam (school level) & & $-3.751 * * *$ & -43.9077 \\
Pre-test - score (student level) & $0.0407 * * *$ & $0.0391 * * *$ & 0.0933 & 0.0871 \\
Pre-test - time (student level) & $-0.0002 * * *$ & $-0.0003^{* * *}$ & $-0.0047 * * *$ & $-0.0048 * * *$ \\
Average pre-test (school level) & & $0.0566 * *$ & -0.14 \\
Number of teachers per pupil (FTE - school level) & & -0.016 & -106.419 \\
Costs for materials per pupil (school level) & & -0.357 & -180.326 \\
Dropout percentage (school level) & & $0.0367 * * *$ & -4.649 \\
$\%$ Disadvantaged students (school) & & -0.0135 & $0.736 * *$ \\
\% Supportive ability track (school) & $30.3286 * * *$ & $23.647 * * *$ & $629.9820 * * *$ & $565.3156 * *$ \\
Constant & Class & Class & Class & Class \\
Fixed effects & 9898 & 9898 & 9898 \\
Number of observations & 0.1447 & 0.1376 & 0.176 & 0.174 \\
$R^{2}$-adjusted & & & 9892 \\
\hline
\end{tabular}

FTE $=$ full time equivalent.

${ }^{*} p<0.05 ;{ }^{*} p<0.01 ;{ }^{* *} p<0.001$

heterogeneities at class level (e.g., due to the teacher, peer effects or ability tracking) are accounted for.

Additional variables are added to models 2 and 4 . This confirms the earlier results. In addition, it shows that the more disadvantaged students a school has, the more intensive the CAI tool is used. It is also remarkable that in schools with more teachers per student, there are less subjects and exercises made. While this correlation is insignificant, it might weakly suggest that teachers and CAI tools are substitutes.

The findings confirm the first hypothesis: schools with lower educational attainments use computerassisted learning programs more frequently in order to catch up in learning outcomes.

\section{Does more intense exposure to the CAl tool cause higher test scores?}

\section{IV analysis}

The intensity by which a student participates in the CAI tool is in an unobserved way correlated to the extent to which the school, and in particular the teacher, stimulates the use of the software. This is also acknowledged by Hennessy, Ruthven, and Brindley (2005) who scrutinized the role of the teacher and found some evidence that the teacher plays an important role in the way that educational technology is used in the classroom. More specifically, the teacher's attitude towards, as well as his acquaintance with, the use of educational technology determines to a considerable extent (1) what educational technology is chosen, (2) how the educational technology will be used in the classroom, and (3) how the pupils will use the technology. This finding of the teachers' crucial role in the implementation and the choice of use of educational technology has consistently been found across earlier studies (see Section 2). Given the unobserved heterogeneity, simply regressing the number of exercises by the student on the test scores would therefore be an endogenous regression.

Because of the lack of experimental data, an IV approach is the best procedure to remove the endogenous part in the regression. To obtain an instrument, we start from earlier work by Spiezia (2010) and Rouse et al. (2004). The former was able to make a good distinction between the different uses and the intensity levels of usage. The latter apply the participation in a CAI tool as an instrument. In the current setting, this implies that the intensity of the participation in the program would be a good instrument. We make this operational by the number of passed subjects. For example, a student who wrote only two subjects is less exposed to the program than a student who wrote subject tests for all subjects. The number of subjects that the student passed is therefore strongly correlated to the number of exercises in the CAI program (significant correlation at $1 \%$ level of .36), while it does not have a direct effect (although an indirect via the number of exercises) on the test scores. 
We define the instrument in two complementary ways. Both specifications are at the individual level. First, we consider the participation in the program as a dummy variable. Only students participating to all or all-but-one of the subjects (instrument $=1$ ) and students participating to less than two subjects (instrument $=0$ ) are included in the analysis (resulting in 5478 observations; see Table 1). A second specification of the instrument consists of considering the number of passed subjects as a continuous variable. From the descriptive statistics in Table 1, we learn that the average student wrote three subjects while $75 \%$ of the students passed three subjects.

\section{First stage tests}

We follow some standard tests to examine the adequacy of the instrument. First consider the (Durbin)$\mathrm{Wu}-$ Hausman test (numerically equivalent to the standard Hausman test) that examines whether the OLS (Ordinary Least Squares) and IV estimates are different. If they differ significantly, we can conclude that $X$ is an endogenous variable. In our application, the regressor is clearly endogenous as the $\mathrm{Wu}$-Hausman $F$-test equals for the dichotomous specification 130.32, $F(1,6547)$, and 462.92 for the continuous specification,
$F(1,12022)$. The Durbin-Wu-Hausman chi-square test equals 127.86 [chi-sq(1)] and 445.91, respectively.

Second, the Anderson LM statistic, which tests the underidentification, equals 3718.93 for the dual instrument and 5914.80 for the continuous instrument, such that the equation is identified, that is, the excluded instruments are correlated with the endogenous regressors. Furthermore, the Sargan statistic suggests that there is no overidentification. This also holds if more control variables are included (see model specifications 2, 4 and 5 below).

Third, the Cragg-Donald Wald test indicates that the instrument is a strong instrument. Its $F$-statistic equals 8598.53 in the case of a dichotomous specification and 1.2E04 in case of the continuous specification.

In sum, given the strong correlation of the instrument with the endogenous regressor, the tests indicate that the instrument is a valid and strong instrument which can be applied in the IV analysis.

\section{Results}

The results of the IV analysis are presented in Table 3. The first two model specifications present the results for the dichotomous instrument, while the last three model specifications present the results for the

Table 3. Instrumental Variable Analysis With Class and School Fixed Effects

\begin{tabular}{|c|c|c|c|c|c|}
\hline Independent variable: post-test scores & Model 1 & Model 2 & Model 3 & Model 4 & Model 5 \\
\hline Number of exercises & $0.0007 * * *$ & $0.0007 * * *$ & $0.0008 * * *$ & $0.0006 * * *$ & $0.0006 * * *$ \\
\hline Pre-test - score (student level) & $0.0049 * * *$ & $0.0027 * * *$ & $0.0051 * * *$ & $0.0028 * * *$ & $0.0027 * * *$ \\
\hline Pre-test - time (student level) & & $0.0000 * * *$ & & $0.0000 * * *$ & $0.0000 * * *$ \\
\hline Average national exam (school level) & & 0.0701 & & $0.1208^{*}$ & (Omitted) \\
\hline Average school exam (school level) & & $0.247 * *$ & & $0.1197 *$ & (Omitted) \\
\hline $\begin{array}{l}\text { Number of teachers per student } \\
\text { (FTE - school level) }\end{array}$ & & 0.501 & & 0.379 & (Omitted) \\
\hline $\begin{array}{l}\text { Costs for materials per student } \\
\text { (school level) }\end{array}$ & & $-0.828 * * *$ & & $-0.642 * * *$ & (Omitted) \\
\hline Dropout percentage (school level) & & $0.0579 * *$ & & -0.021 & (Omitted) \\
\hline$\%$ Disadvantaged students (school) & & 0.0016 & & $0.0015^{* *}$ & (Omitted) \\
\hline$\%$ Supportive ability track (school) & & -0.0117 & & 0.0008 & (Omitted) \\
\hline Constant & $0.3060 * * *$ & $-1.649 * *$ & $0.2993 * * *$ & $-1.1262 * *$ & $0.4284 * * *$ \\
\hline Instrument & $\begin{array}{l}\text { Dummy (little - } \\
\text { extensive) }\end{array}$ & $\begin{array}{l}\text { Dummy (little - } \\
\text { extensive) }\end{array}$ & Continuous & Continuous & Continuous \\
\hline Fixed effects & & Class & & Class & $\begin{array}{c}\text { Class and } \\
\text { school }\end{array}$ \\
\hline Number of observations & 5478 & 5478 & 9898 & 9898 & 9898 \\
\hline$R^{2}$-adjusted & 0.0817 & & 0.0765 & & \\
\hline
\end{tabular}

$\mathrm{FTE}=$ full time equivalent.

${ }^{\star} p<0.1 ;{ }^{*} p<0.05 ;{ }^{* * *} p<0.01$. 
continuous instrument. To capture the observed and unobserved heterogeneities, we include class fixed effects (models 2 and 4) and class and school fixed effects (model 5). The results are robust across all model specifications.

We observe that, instrumented for the participation in the CAI tool, making more exercises leads to higher test scores. The coefficient is positive and significant for all specifications. As the average student makes 50 exercises (see Table 1), he/she increases the post-test scores by $0.035(0.0007 \times 50)$, which is about $3.5 \%$ as the post-test ranges between 0 and 1 . Table 3 further reveals that, as expected, students with higher abilities, that is, a higher pre-test score, also have higher test scores. Controlled for class fixed effects, we observe that schools with higher national and school exam results have significantly higher test scores of students. Students in schools with higher material costs per student have lower test results, while schools with more teachers per students do not seem to have significantly higher test results. The IV regression further reveals that, given the ability of the student, the percentage of students coming from disadvantaged neighbourhoods increases the posttest scores. The latter three observations are only significant in model specification 4 . The remaining control variables are not significantly different from 0 .

In sum, we find that, given the participation to the CAI tool, making more exercises leads to higher test results. Working with a CAI tool seems therefore effective.

\section{Conclusion and policy recommendations}

Whereas ICT infrastructure has improved considerably in secondary schools during the last decades, there still remains the enormous challenge for teachers and educational stakeholders to integrate this infrastructure in the teaching and learning activities. Undoubtedly, a key role in the integration of educational technology is played by the two stakeholders most involved in the education process: the teachers and the pupils. Overall, the literature shows that teachers play a critical role in determining (1) whether technology will be used in the classroom and (2) if so, how the educational technology will be exactly used.

As an empirical contribution, this paper exploited the variation in the use of a CAI tool. In particular, it examined the effectiveness of an adaptive Dutch CAI tool for mathematics in lower secondary education (called Gotit?!). We observed that schools with, on average, lower attainments (as measured on nationwide standardized exams) rely more on the novel CAI tool than schools with higher attainments. This suggests that schools see CAI tools as a way to catch up in learning outcomes. This finding is confirmed by the observation that schools with a higher share of students from disadvantaged neighbourhoods (as defined by the central government) are more frequently working with the tool. Again, this suggests that schools are effectively using the tool to differentiate among students.

Moreover, this paper examined whether a higher exposure to the program leads to higher test outcomes using an IV approach. We observe that, given the participation to the CAI tool, making more exercises leads to higher test results. Working with a CAI tool seems therefore effective.

\section{Policy recommendations}

Given the important role of teachers, it is crucial that teachers dispose of adequate knowledge for using educational technology effectively. Therefore, it is important that policymakers as well as school directors invest both resources and time in the training of teachers. The results of this paper also suggest that policymakers can more actively encourage the use of ICT for schools with poor learning outcomes or with a diverse student population. As the ICT hardware is nowadays available in most schools, ICT should be used in the most effective and efficient way. This paper shows that adaptive CAI tools might be an effective tool to increase learning outcomes.

\section{Acknowledgements}

We would like to thank Andre de Moor, Rob Sudmeijer, Irene Pouw, Roelie Kruis, Eline Sneyers and Wim Groot for valuable comments and discussions. Kristof De Witte and Carla Haelermans gratefully acknowledge financial support from the Dutch Ministry of Education, Culture and Science.

\section{Note}

${ }^{1}$ There are several dimensions along which the literature on the effectiveness of computer-assisted instruction (CAI) can be classified. In this review, we focus on the effectiveness of CAI tools for mathematics. 


\section{References}

Alavi, M., \& Leidner, D. E. (2001). Research commentary: Technology-mediated learning - a call for greater depth and breadth of research. Information Systems Research, 12(1), 1-10.

Angrist, J., \& Lavy, V. (2002). New evidence on classroom computers and pupil learning. The Economic Journal, 112(482), 735-765.

Arbaugh, J. B. (2002). Managing the on-line classroom: A study of technological and behavioral characteristics of web-based MBA courses. Journal of High Technology Management Research, 13, 203-223.

Bandura, A. (1997). Self-efficacy: The exercise of control. Englewood Cliffs, NJ: Prentice-Hall.

Banerjee, A., Cole, S., Duflo, E., \& Linden, L. (2007). Remedying education: Evidence from two randomized experiments in India. Quarterly Journal of Economics, 122(3), 1235-1264.

Beal, C. R., Arroyo, I. M., Cohen, P. R., \& Woolf, B. P. (2010). Evaluation of AnimalWatch: An intelligent tutoring system for arithmetic and fractions. Journal of Interactive Online Learning, 9(1), 64-77.

Biagi, F., \& Loi, M. (2013). Measuring ICT use and learning outcomes: Evidence from recent econometric studies. European Journal of Education, 48(1), 28-42.

Blok, H., Oostdam, R., Otter, M. E., \& Overmaat, M. (2002). Computer-assisted instruction in support of beginning reading instruction: A review. Review of Educational Research, 72, 101-130.

Bouck, E. C., \& Flanagan, S. M. (2009). Assistive technology and mathematics: What is there and where can we go in special education. Journal of Special Education Technology, 24(2), 17-30.

Campuzano, L., Dynarski, M., Agodini, R., \& Rall, K. (2009). Effectiveness of reading and mathematics software products: Findings from two student cohorts. Institute of Education Sciences, National Center for Education Evaluation and Regional Assistance, Washington, DC.

Cheng, Y. M. (2011). Antecedents and consequences of e-learning acceptance. Information Systems Journal, 21(3), 269-299.

Cheung, A. C., \& Slavin, R. E. (2013). The effectiveness of educational technology applications for enhancing mathematics achievement in K-12 classrooms: A meta-analysis. Educational Research Review, 9, 88-113.

Christmann, E. P., \& Badgett, J. L. (2000). The comparative effectiveness of CAI on collegiate academic performance. Journal of Computing in Higher Education, 11(2), 91-103.

Christmann, E. P., \& Badgett, J. L. (2003). A meta-analytic comparison of the effects of computer-assisted instruction on elementary students' academic achievement. Information Technology in Childhood Education Annual, 1, 91-104.

Commissie Meijerink. (2008). Over de drempels met taal en rekenen - Hoofdrapport van de expertgroep doorlopende leerlijnen taal en rekenen. Enschede. Retrieved from http://www.slo.nl/nieuws/dll/Hoofdrapport.pdf/

Condie, R., \& Munro, B. (2007). The impact of ICT in schools - a landscape review. Becta Research Report.

Cox, M. J., \& Abbott, C. (Eds.). (2004). ICT and attainment - a review of the research literature. Coventry, Becta/ London: DfES.

Cox, M. J., \& Marshall, G. (2007). Effects of ICT: Do we know what we should know? Education and Information Technologies, 12(2), 59-70

Davis, F. D. (1989). Perceived usefulness, perceived ease of use, and user acceptance of information technology. MIS Quarterly, 13, 319-340.

De Witte, K., Geys, B., \& Solondz, C. (2014). Public expenditures, educational outcomes and grade inflation: Theory and evidence from a policy intervention in the Netherlands. Economics of Education Review, 40, 152 166.

Doerr, H. M., \& Zangor, R. (2000). Creating meaning for and with the graphing calculator. Educational Studies in Mathematics, 41(2), 143-163.

Dynarski, M., Agodini, R., Heaviside, S., Novak, T., Carey, N., Campuzano, L., . . . Sussex, W. (2007). Effectiveness of reading and mathematics software products: Findings from the first student cohort. Institute of Education Sciences, National Center for Education Evaluation and Regional Assistance, Washington, DC.

Edwards, M. T., \& Quesada, A. (2007). Dueling (Dualing) solids: Enhancing student and teacher geometrical understanding with CABRI 3D. Proceedings of the Nineteenth Annual International Conference on Technology in Collegiate Mathematics (ICTCM), February 15-18, 2007, Boston, MA.

European Commission. (2000). Communication from the Commission-e-Learning - Designing tomorrow's education. $\operatorname{COM}(2000) 318$ final.

European Schoolnet. (2013). Survey of schools: ICT in education. Retrieved from http://www.eun.org/ publications (last accessed 3 September 2014).

Fuchs, T., \& Wößmann, L. (2004). Computers and student learning: Bivariate and multivariate evidence on the availability and use of computers at home and at school. CESifo Working Paper 1321, Munich: CESifo.

Fulk, J., Schmitz, J., \& Steinfield, C. W. (1990). A socia influence model of technology use. In J. Fulk \& 
C. Steinfield (Eds.), Organizations and communication technology (pp. 117-141). Newbury Park, CA: Sage.

Goldberg, A., Russell, M., \& Cook, A. (2003). The effect of computers on student writing: A meta-analysis of studies from 1992-2002. The Journal of Technology, Learning, and Assessment, 2(1), 1-51.

Hennessy, S., Ruthven, K., \& Brindley, S. (2005). Teacher perspectives on integrating ICT into subject teaching: Commitment, constraints, caution and change. Journal of Curriculum Studies, 37, 155-192.

Honey, M., Culp, K. M., \& Carrigg, F. (2000). Perspectives on technology and education research: Lessons from the past and present. Journal of Educational Computing Research, 23(1), 5-14.

Johnson, R. D., Hornik, S., \& Salas, E. (2008). An empirical examination of factors contributing to the creation of successful e-learning environments. International Journal of Human-Computer Studies, 66, 356-369.

Jonassen, D. H., Peck, K. L., \& Wilson, B. G. (1999). Learning with technology: A constructivist perspective. Upper Saddle River, NJ: Prentice-Hall.

Kaput, J., Hegedus, S., \& Lesh, R. (2007). Technology becoming infrastructural in mathematics education. In R. Lesh, E. Hamilton, \& J. Kaput (Eds.), Foundations for the future in mathematics education (pp. 173-192). Mahwah, NJ: Lawrence Erlbaum Associates.

Kebritch, M., Hirumi, A., \& Bai, H. (2010). The effects of modern mathematics computer games on mathematics achievement and class motivation. Computers and Education, 55(2), 427-443.

Koedinger, K. R., McLaughlin, E. A., \& Heffernan, N. T. (2010). A quasi-experimental evaluation of an on-line formative assessment and tutoring system. Journal of Educational Computing Research, 43(4), 489-510.

Köklü, O., \& Topçu, A. (2012). Effect of Cabri-assisted instruction on secondary school students' misconceptions about graphs of quadratic functions. International Journal of Mathematical Education in Science and Technology, 43(4), 1-13.

Kubiatko, M., \& Vlckova, K. (2010). The relationship between ICT use and science knowledge for Czech students: A secondary analysis of PISA 2006. International Journal of Science and Mathematics Education, 8, 523543.

Kulik, C. C., \& Kulik, J. A. (1991). Effectiveness of computer-based instruction: An updated analysis. Computers in Human Behavior, 7, 75-94.

Kulik, J. A. (1994). Meta-analytic studies of findings on computer-based instruction. In E. L. Baker \& H. F. O’Neill (Eds.), Technology assessment in education and training (pp. 9-33). Hillsdale, NJ: Lawrence Erlbaum.
Kulik, J. A. (2003). Effects of using instructional technology in elementary and secondary schools: What controlled evaluation studies say. SRI International Report.

Leuven, E., Lindahl, M., Oosterbeek, H., \& Webbink, D. (2004). The effect of extra funding for disadvantaged pupils on achievement. The Review of Economics and Statistics, 89, 721-736.

Liu, S. H., Liao, H. L., \& Pratt, J. A. (2009). Impact of media richness and flow on e-learning technology acceptance. Computers and Education, 52, 599-607.

Luu, K., \& Freeman, J. G. (2011). An analysis of the relationship between information and communication technology (ICT) and scientific literacy in Canada and Austria. Computers and Education, 56, 1072-1082.

Macdonald, J. (2004). Developing competent e-learners: The role of assessment. Assessment and Evaluation in Higher Education, 29(2), 215-226.

Machin, S., McNally, S., \& Silva, O. (2007). New technology in schools: Is there a payoff? The Economic Journal, 117(522), 1145-1167.

Marakas, G. M., Yi, M. Y., \& Johnson, R. D. (1998). The multilevel and multifaceted character of computer selfefficacy: Toward clarification of the construct and an integrative framework for research. Information Systems Research, 9(2), 126-163.

McAlister, M., Dunn, J., \& Quinn, L. (2005). Student teachers' attitudes to and use of computers to teach mathematics in the primary classroom. Technology, Pedagogy and Education, 14(1), 77-105.

Murphy, R., Penuel, W., Means, B., Korbak, C., \& Whaley, A. E-DESK: A review of recent evidence on the effectiveness of discrete educational software. Menlo Park, CA: SRI International, 2001.

Notten, N., \& Kraaykamp, G. (2009). Home media and science performance: A cross national study. Educational Research and Evaluation: An International Journal on Theory and Practice, 15, 367-384.

Paas, F., Renkl, A., \& Sweller, J. (2003). Cognitive load theory and instructional design: Recent developments. Educational Psychologist, 38(1), 1-4.

Papastergiou, M. (2009). Digital game-based learning in high school computer science education: Impact on educational effectiveness and student motivation. Computers and Education, 52(1), 1-12.

Piaget, J. (1970). Science of education and the psychology of the child. New York, NY: Orion Press.

Pilli, O., \& Aksu, M. (2013). The effects of computerassisted instruction on the achievement, attitudes and retention of fourth grade mathematics students in North Cyprus. Computers and Education, 62, 62-71. 
Pituch, K. A., \& Lee, Y. K. (2006). The influence of system characteristics on e-learning use. Computers and Education, 47(2), 222-244.

Potocki, A., Ecalle, J., \& Magnan, A. (2013). Effects of computer-assisted comprehension training in less skilled comprehenders in second grade: A one-year follow-up study. Computers and Education, 63, 131-140.

Rayne, R., \& Baggott, G. (2004). Computer-based and computer-assisted tests to assess procedural and conceptual knowledge.

Reimer, K., \& Mayer, P. S. (2005). Third-graders learn about fractions using virtual manipulatives: A classroom study [Electronic version]. The Journal of Computers in Mathematics and Science Teaching, 24(1), 5-25.

Roca, J. C., \& Gagné, M. (2008). Understanding e-learning continuance intention in the workplace: A selfdetermination theory perspective. Computers in Human Behavior, 24(4), 1585-1604.

Roschelle, J., Shechtman, N., Tatar, D., Hegedus, S., Hopkins, B., Empson, S., . . Gallagher, L. (2010). Integration of technology, curriculum, and professional development for advancing middle school mathematics: Three large-scale studies. American Educational Research Journal, 47(4), 833-878.

Rouse, C. E., Krueger, A. B., \& Markman, L. (2004). Putting computerized instruction to the test: A randomized evaluation of a 'scientifically-based' reading program. Economics of Education Review, 23(4), 323-338.

Sahasrabudhe, V., \& Kanungo, S. (2014). Appropriate media choice for e-learning effectiveness: Role of learning domain and learning style. Computers and Education, 76, 237-249.

Schacter, J. (2001). The impact of educational technology on student achievement: What the most current research has to say. Santa Monica, CA: Milken Exchange on Education Technology.

Shute, V. J., \& Zapata-Rivera, D. (2007). Adaptive technologies. In J.M. Spector, M.D. Merrill, J. van Merriënboer,
M.P. Driscoll (Eds.), Handbook of research for educational communications and technology (pp. 277-294). Abingdon, UK: Taylor \& Francis group.

Skinner, B. F. (1954). The science of learning and the art of teaching (pp. 99-113). Cambridge, MA: American Psychological Association.

Skinner, B. F. (1958). Teaching machines. Science, 128(96977), 137-158.

Spiezia, V. (2010). Does computer use increase educational achievements? Student-level evidence from PISA. OECD Journal: Economic Studies, 2010, 1-22.

Sun, P. C., Tsai, R. J., Finger, G., Chen, Y.-Y., \& Yeh, D. (2008). What drives a successful e-Learning: An empirical investigation of the critical factors influencing learner satisfaction. Computers and Education, 50, 1183 1202.

Swan, K. (2003). Learning effectiveness online: What the research tells us. In J. Bourne, J.C. Moore (Eds.), Elements of quality online education, practice and direction (Vol. 4, pp. 13-45). Needham, MA: Sloan Center for Online Education.

Sweller, J. (1988). Cognitive load during problem solving: Effects on learning. Cognitive Science, 12(2), 257-285.

Van Merriënboer, J. J., \& Ayres, P. (2005). Research on cognitive load theory and its design implications for e-learning. Educational Technology Research and Development: ETR \& D, 53(3), 5-13.

Wenglinsky, H. (1998). Does it compute? The relationship between educational technology and student achievement in mathematics. Princeton, NJ: Educational Testing Service.

Wittwer, J., \& Senkbeil, M. (2008). Is students' computer use at home related to their mathematical performance at school? Computers and Education, 56, 736-746.

Wu, J., Tsai, R. J., Chen, C. C., \& Wu, Y. (2006). An integrative model to predict the continuance use of electronic learning systems: Hints for teaching. International Journal on E-Learning, 5(2), 287-302. 